\title{
A CIDADE DOS RICOS: FINANCEIRIZAÇÃO E A CAPTURA DO ESPAÇO PELA ELITE GLOBAL
}

\author{
João Carlos Carvalhaes Monteiro* \\ *Universidade Federal Fluminense, Departamento de Geografia, Niterói, RJ, Brasil
}

ATKINSON, R. Alpha City: How London Was Captured by the Super-Rich. London; New York: Verso, 2020. 256p

Nos anos 1960, a socióloga Ruth Glass cunhou o termo gentrificação ao identificar a substituição de famílias operárias por outras de renda mais elevada em distritos populares da área central de Londres (GLASS, 1964). Quase seis décadas depois, a capital britânica tornou-se o epicentro do mercado financeiro global e registra em seu território o recorde mundial de milionários por habitante. A valorização vertiginosa do espaço urbano, reflexo do aporte maciço de capital estrangeiro, em especial no setor imobiliário, ameaça até mesmo a classe média londrina, no passado apontada pela autora como o principal agente da gentrificação.

Em seu mais recente livro, Rowland Atkinson, professor do Departamento de Estudos Urbanos e Planejamento da Universidade de Sheffield (Inglaterra), discorre sobre o processo de elitização de Londres, ou, conforme sugere o subtítulo da obra, como a cidade foi capturada pelos super-ricos. Há pelo menos duas décadas esse autor desenvolve pesquisas sobre segregação, gentrificação e criminalidade urbana. Um dos temas recorrentes em seus trabalhos, que ganha atenção especial no livro em análise, é a apropriação do espaço urbano pelas elites e os impactos dessa ação sobre os mais pobres.

Nas páginas introdutórias, Atkinson lembra que Londres é o exemplo por excelência de metrópole que se desenvolveu sob o jugo da aristocracia e da burguesia, amparadas no imperialismo britânico, em especial no período vitoriano. No pós-guerra, no entanto, as elites tiveram sua hegemonia restringida pela ação de governos trabalhistas e social-democratas, que fortaleceram o Estado de bem-estar social e promoveram o sentimento de responsabilidade compartilhada 
diante dos problemas sociais. Mas a crise financeira global de 2008 representou uma reviravolta no contexto político e na evolução urbana de Londres, culminando naquilo que o autor identifica como o resgate do controle da cidade pelas elites. Por um lado, a crise respaldou o discurso da austeridade, viabilizando cortes em programas e em investimentos sociais que acabaram por deteriorar a qualidade de vida das camadas populares - em especial suas condições de habitabilidade, pelo desmantelamento do sistema público de moradia social. Por outro, justificou a implementação de medidas pró-mercado, incentivando a entrada de capitais por meio de facilidades fiscais e da remoção de regulações sobre transações financeiras. Criaram-se, assim, as condições ideais para a captura da cidade pela elite global, um processo que contou com ampla conivência de atores políticos locais. Esse é o ponto de partida de Atkinson.

Os primeiros capítulos trazem uma reflexão abrangente sobre a captura de Londres pelos super-ricos, o que o autor chama de "colonização pelo capital”. Foi isso que ditou os rumos da metrópole na última década, sobretudo por meio da internacionalização do mercado imobiliário local. Abordam ainda os valores e pressupostos ideológicos que constituem esse modelo, no qual promotores privados são exaltados como salvadores da economia da cidade e que atrela seu dinamismo e vitalidade ao aporte de capital estrangeiro.

É nesse sentido que Atkinson apresenta a hipótese sobre a primazia de Londres na hierarquia das cidades globais e, assim, atualiza o debate que tem como marco o livro The Global City, de Sassen (1991), publicado há três décadas. Para o pesquisador, o projeto de desenvolvimento assumido pela capital britânica transformou-a na integrante mais poderosa do círculo restrito de metrópoles que centralizam o poder econômico mundial: Londres, portanto, "não é simplesmente uma das cidades globais, mas é $a$ cidade global, o membro supremo de um grupo que produz e acolhe vastas fortunas em meio a uma economia globalizada dirigida cada vez mais pelas finanças. Resumindo, Londres é a cidade alfa” (p. 9).

Uma descrição dessa elite londrina e de sua territorialização é apresentada nos três primeiros capítulos. O grupo dos super-ricos da "cidade alfa”, historicamente composto das tradicionais famílias aristocráticas britânicas, abarca agora magnatas da mídia, do comércio e da indústria, oligarcas russos, indivíduos ligados a redes de crime organizado, barões do petróleo e outros bilionários associados aos mercados de commodities. A crise financeira de 2008, sustenta o autor, não afetou esse grupo seleto; pelo contrário, incrementou suas riquezas. Por oferecer um ambiente favorável e pouco regulado para os investimentos internacionais, Londres se tornou um porto seguro para acolher esse capital abundante em circulação. Como consequência, em uma década, a paisagem da cidade e seu ambiente construído foram redefinidos pela internacionalização do mercado imobiliário: 
"algumas das mais espetaculares mudanças proporcionadas pelos ricos e seus investimentos podem ser observadas nos vários novos edifícios, resultados daquele que talvez seja o mais dramático programa de construção empreendido na cidade no período pós-guerra” (p. 19).

Três debates, descritos a seguir, ganham destaque no livro.

O primeiro versa sobre o dinheiro ilícito que contribuiu para o boom imobiliário das últimas décadas e que transformou a cidade num "gigantesco cassino para o capital” (p. 83). Por detrás dos edifícios novos e opulentos, muitos deles propriedades de firmas offshore estabelecidas em paraísos fiscais, escondem-se bilhões de libras esterlinas geradas em operações criminosas: Londres seria, assim, o palco de uma vasta economia subterrânea e "oferece aquilo que muitos experts acreditam ser o mais avançado sistema de lavagem de dinheiro e crime financeiro no mundo" (p. 85). O capítulo 4 trata especificamente desse tema, apresentando diversos dados sobre o dinheiro ilícito investido no espaço urbano, a cumplicidade de autoridades que fazem vista grossa para denúncias e a inação de políticos que se mostram pouco interessados em saber a origem dos investimentos que aportam na cidade.

Outro assunto de interesse é o da hipermobilidade dos super-ricos, tratado especialmente no capítulo 5. Nele, Atkinson analisa a excepcional mobilidade desse grupo e sua capacidade de fácil acesso a todos os espaços do planeta, uma característica que reforça o status privilegiado de Londres perante as demais metrópoles globais: "A cidade alfa não poderia existir sem uma sofisticada engrenagem que oferece aos ricos a oportunidade de meios de transporte rápidos, confortáveis e privados” (p. 109). Sobre esse tema, o autor comenta a importância dos fluxos estabelecidos por uma infraestrutura de transportes que permite aos milionários acessar aeroportos exclusivos para seus jatos particulares, dispor de ampla gama de conexões aéreas com outros destinos globais "bem classificados" e usufruir de autoestradas de alta velocidade que aproximam os diferentes bairros abastados da cidade. Esses fluxos criados sob medida para as necessidades e desejos dessa elite removem dela a sensação de coabitação com outras classes sociais. Cria-se, assim, um simulacro do urbano que mascara a realidade precária de muitos dos seus concidadãos, comedindo o sentimento de empatia dos super-ricos em face dos problemas da maioria dos londrinos.

Por último, no capítulo 6, Atkinson analisa a paranoia das elites globais no que se refere à segurança e suas consequências no espaço público da cidade. "A captura de Londres pelos ricos é em parte expressa por meio de uma transformação por atacado de muitas áreas que passam a ser organizadas em torno do princípio da segurança” (p. 145). Apesar de ter um dos mais baixos índices de 
violência do mundo entre as metrópoles do seu porte, Londres transformou-se numa prisão autoconstruída pelos milionários, que se cercam de aparatos eletrônicos de vigilância, transformam suas mansões em verdadeiros bunkers e se enclausuram em condomínios fechados comparados a enclaves fortificados. A cidade promete ser um ambiente de baixo risco, não apenas para os investimentos, mas também para os milionários que nela residem e circulam. E a resposta da administração local a essa demanda das elites é oferecer um planejamento urbano que se expressa por meio daquilo que o autor considera ser um novo tipo de antiurbanismo: "uma revolta invisível das elites - uma espécie de insurreição expressa fisicamente pelas barricadas erguidas para defender as zonas antiurbanas dos super-ricos” (p. 162). Para esses indivíduos, aspectos comuns da vida urbana, como a diversidade social e a imprevisibilidade cotidiana, devem ser evitados em nome da privacidade, da esterilidade e da exclusividade do convívio com seus semelhantes.

Atkinson encerra o livro discorrendo sobre os impactos dessa elitização sobre a maior parte da população da cidade: trabalhadores precarizados, jovens marginalizados e imigrantes ilegais. 'O cotidiano dos 'de baixo' se tornou uma espécie de inferno urbano, enquanto os ricos continuam a extrair cada vez mais riquezas e a desfrutar tranquilamente seus estilos de vida” (p. 165). Se no passado havia uma corresponsabilidade ante os problemas dos mais pobres, justificando investimentos públicos para atenuar as precariedades, que funcionavam como freio a conflitos sociais, hoje a riqueza exorbitante permite que os milionários contornem compromissos com a esfera pública e desconsiderem qualquer tipo de agenda social.

Em paralelo à força de atração de capitais, Londres encarna também uma força centrípeta que expele os pobres e a classe média para as franjas da metrópole. Desamparados pelo encolhimento de programas sociais e incapazes de arcar com os altos custos dos aluguéis, todos os que não se beneficiaram da política de hiperfinanceirização compõem o retrato mais bem-acabado da desigualdade na "cidade alfa”: mais de um quarto dos lares londrinos está abaixo da linha da pobreza.

Em uma das passagens mais interessantes da conclusão, o autor descreve a decisão política de transferir bens e terrenos públicos para promotores privados: bibliotecas, hospitais, escolas, equipamentos comunitários e até mesmo amplos conjuntos habitacionais, que garantem uma rede de proteção para os mais vulneráveis, estão sendo demolidos a fim de abrir espaço para grandes projetos imobiliários. A gentrificação, ressalta Atkinson, deixou de ser um fenômeno pontual como era nos anos 1960, quando atingia apenas alguns bairros de Londres, e se tornou um fenômeno generalizado impulsionado pelas autoridades locais.

Os espaços da riqueza são, também, construídos por meio da destruição do sentido dos lugares e do seu cotidiano. O autor descreve que muitos dos locais 
transformados pelo capital financeiro mundializado se tornaram bairros-fantasmas, quer pelo desprezo dos ricos pelo espaço público, quer pela baixa taxa de ocupação da maioria dos imóveis recentemente construídos. Concebidos como meros ativos financeiros, os grandes empreendimentos muitas vezes ficam sem nenhum tipo de uso, conformando aquilo que Atkinson denomina necroarquitetura, isto é, "uma forma arquitetônica gerada com base na necessidade dos ricos de acomodar seu dinheiro, mas não seus corpos, literalmente uma espécie de espaço morto" (p. 97).

Para além da atualidade dos dados e da riqueza de detalhes, o livro tem significativa relevância por oferecer a análise de um grupo social particular: as elites, cujas ações historicamente orientam os destinos das cidades e, no entanto, são escassamente pesquisadas no âmbito dos Estudos Urbanos. É notável nas Ciências Sociais a existência de uma tradição de pesquisas sobre as populações vulneráveis, suas práticas sociais, suas formas de organização, sua atividade política e seus espaços de vida. Porém, pesquisas sobre esses mesmos temas quando se trata de grupos sociais abastados são escassas.

Pode-se justificar essa carência pela dificuldade de acesso aos espaços da riqueza e a seus atores, ou ainda pelo receio que esses indivíduos têm de seus cotidianos indagados e publicizados. A relutância dos ricos em colaborar como “objeto de estudo" talvez seja um empecilho de peso para pesquisadores interessados no tema. No passado, no entanto, alguns autores pavimentaram esse caminho. Um dos exemplos notáveis é o do casal de sociólogos Michel Pinçon e Monique Pinçon-Charlot, que há mais de três décadas estuda as elites francesas e que já publicou mais de quinze livros sobre o tema. Um dos mais conhecidos, intitulado Les Ghettos du Gotha: comment la bourgeoisie défend ses espaces, aborda as estratégias empregadas pela elite parisiense para proteger seus bairros exclusivos, em especial os chamados beaux quartiers (PINÇON; PINÇON-CHARLOT, 2007). No Brasil, a pesquisa da antropóloga Teresa Caldeira sobre as novas formas de segregação espacial em São Paulo tangencia o tema dos espaços da riqueza, ao analisar a reclusão das elites em enclaves fortificados (CALDEIRA, 2000).

Duas coletâneas recentes também trazem reflexões importantes para o debate. A primeira, Geographies of the Super-rich, reúne doze textos, sobretudo de geógrafos majoritariamente focados na espacialização das elites em cidades do capitalismo central (HAY, 2013). A segunda, com catorze capítulos, é intitulada Cities and the Super-rich: Real Estate, Elite Practices, and Urban Economies, com reflexões atualizadas sobre as ações da elite no pós-crise financeira de 2008 (FORREST; KOH; WISSINK, 2017). Ambas as obras debatem a financeirização do espaço urbano, mas a mobilização desses trabalhos como chave interpretativa para a realidade brasileira nos parece inadequada, visto que o processo descrito 
em cidades como Londres, Tóquio e Nova York é significativamente distinto do que ocorre nas metrópoles nacionais.

No momento em que proliferam estudos a respeito do processo de gentrificação e em que o debate acerca de temas como segregação ganha novas perspectivas, é oportuno construirmos uma agenda de pesquisa sobre os espaços da riqueza e seus representantes. É preciso extrapolar as análises consolidadas há décadas sobre os territórios populares e periféricos que até agora privilegiaram uma interpretação parcial e incompleta da produção do espaço urbano. O exercício intelectual de desvelar as práticas espaciais das elites, em especial nas cidades do capitalismo periférico marcadas por profundas desigualdades, contribui para o esforço de pesquisadores engajados na transformação social.

\section{Referências}

ATKINSON, R. Alpha City: How London Was Captured by the Super-Rich. London; New York: Verso, 2020.

CALDEIRA, T. City of Walls: Crime, Segregation and Citizenship in São Paulo. Berkeley: University of California Press, 2000.

FORREST, R.; KOH, S.; WISSINK, B. (org.). Cities and the Super-rich: Real Estate, Elite Practices, and Urban Economies. New York: Palgrave Macmillan, 2017.

GLASS, R. London: Aspects of Change. London: MacGibbon \& Kee, 1964.

HAY, I. (org.). Geographies of the Super-rich. Cheltenham: Edward Elgar, 2013.

PINÇON, M.; PINÇON-CHARLOT, M. Les Ghettos du Gotha: comment la bourgeoisie défend ses espaces. Paris: Seuil, 2007.

SASSEN, S. The Global City: New York, London, Tokyo. Princeton: Princeton University Press, 1991. 


\section{João Carlos Carvalhaes Monteiro}

Geógrafo pela Universidade Federal Fluminense (UFF), mestre em Planejamento Urbano e Regional pelo Instituto de Pesquisa e Planejamento Urbano e Regional da Universidade Federal do Rio de Janeiro (IPPUR/UFRJ) e doutor em Geografia também pela UFF. Realiza estágio pós-doutoral em Geografia nessa instituição e atua como coordenador do Observatório do Centro de Niterói (Observa Centro).

Email: joaocarlosmonteiro@gmail.com

ORCID: 0000-0002-9550-4302

Submissão: 7 de novembro de 2020.

Aprovação: 3 de fevereiro de 2021.

Como citar: MONTEIRO, J. A cidade dos ricos: financeirização e a captura do espaço pela elite global. Revista brasileira de estudos urbanos e regionais. v.23, E202106, 2021. DOI 10.22296/2317-1529.rbeur.202106

Artigo licenciado sob Licença Creative Commons CC BY-NC 4.0. https://creativecommons.org/licenses/by-nc/4.o/deed.pt_BR 